\title{
ARAHAN PENGELOLAAN DAERAH ALIRAN SUNGAI BERDASARKAN INDEKS BAHAYA EROSI (IBE) SUB DAS PITU RIASE KABUPATEN SIDRAP
}

(Direction of Management of River Flow Area Based on Erosic Hazard Index (EHI) Pitu Riase Sub-District, Sidrap District)

\author{
Andi Nurhawaidah', Amir Tjoneng ${ }^{2}$, Iskandar Hasan ${ }^{2}$ \\ ${ }^{1}$ Mahasiswa Program Pascasarjana Agroekoteknologi, Fakultas Pertanian, Universitas Muslim Indonesia \\ ${ }^{2}$ Dosen Program Pascasarjana Agroekoteknologi, Fakultas Pertanian, Universitas Muslim Indonesia \\ 085239997672, andi.nurhawaida@gmail.com
}

\begin{abstract}
The purpose of this study is 1)Analyzing the level of erosion that occurs in various land uses in the Pitu Riase sub-watershed, Sidrap Regency. 2)Assess tolerable erosion rates (TSL). 3)Analyze the erosion hazard index (EHI).4)Determine recommendations for land use in the Pitu Riase sub-watershed in Sidrap Regency. This research was carried out in the Pitu Riase Sub-watershed, Sidenreng Rappang Regency from February to April 2018. As technology developed, there were several general methods that could be used to predict erosion rates. The USLE (Universal Soil Loss Equation) method is one of the commonly used methods. The results showed that erosion that occurred in the Pitu Riase sub-watershed was 1.8 tons/ha/year for Primary Dryland Forests, 4.97 tons/ha/year in secondary dryland forests, 85.37 tons/ha/year in mixed dryland agriculture, and 58.03 tons/ha/year in shrubs and erosion that can be tolerated is 11.99 tons/ha/year in primary dryland forests, 11.64 tons/ha/year in dryland forests secondary, 8.96 tons/ha/year in mixed dryland agriculture, and 11.35 tons /ha/year in shrubs. EHI in the Pitu Riase sub-watershed is classified as heavy on mixed dry land and scrub. The recommendations for land use in the Pitu Riase sub-watershed in Sidrap Regency for mixed dryland farming are the addition of mulch on agricultural land and the creation of a terrace to reduce erosion.
\end{abstract}

Keywords: DAS, Erosion, conservation, TSL, and IBE

\section{PENDAHULUAN}

Pertanian berkelanjutan adalah sistem pertanian yang mengacu pada pengelolaan sumber daya alam secara optimal termasuk di dalamnya pengelolaan daerah aliran sungai (DAS). Secara topografi, DAS dibagi atas daerah hulu, tengah, dan hilir yang saling terkait. Aktivitas yang terjadi pada daerah hulu akan berdampak terhadap daerah hilir. Sebagai salah satu sumber daya alam, maka sumber daya yang ada pada suatu wilayah DAS dimanfaatkan untuk berbagai kepentingan. Masalah utama kerusakan sumber daya lahan di daerah aliran sungai (DAS) disebabkan oleh erosi. Erosi menyebabkan kerusakan tanah yang meliputi sifat fisik, kimia dan biologi tanah. Penggunaan lahan yang tidak menerapkan kaidah kaidah konservasi membuat proses erosi semakin cepat terjadi.

Adapun Faktor yang sangat berpengaruh terhadap kerusakan DAS adalah semakin banyaknya kasus alih fungsi lahan menjadi pemukiman, 
perkebunan/ pertanian tanpa adanya Dengan tujuan 1) Menganalisis besarnya tindakan konservasi tanah dan air yang tingkat erosi yang terjadi pada berbagai tepat. Pada tahun 2015, Sub DAS Pitu penggunaan lahan di Sub DAS Pitu Riase Riase seluas 1.694,13 ha terdiri dari Kabupaten Sidrap. 2) Mengkaji laju erosi beberapa jenis penutupan lahan yaitu yang dapat ditoleransikan (TSL) di Sub hutan lahan kering sekunder mengalami peningkatan $107 \mathrm{Ha}(6,3 \%)$, hutan lahan kering primer menurun $1,7 \mathrm{Ha}(0,1 \%)$, dan pertanian lahan kering meningkat 68 $\mathrm{Ha}(4 \%)$. Perubahan penggunaan lahan tersebut dapat menyebabkan kondisi hidrologi Sub DAS Pitu Riase semakin menurun dimana erosi yang terjadi di Sub DAS Pitu Riase adalah sebesar 133 ton/ha/thn.

Berdasarkan hal tersebut di atas, penulis tertarik melakukan penelitian mengenai Arahan Pengelolaan Daerah Aliran Sungai berdasarkaan Indeks Bahaya Erosi (IBE) Sub DAS Pitu Riase Kabupaten Sidrap dengan rumusan masalah: 1) Berapa besar tingkat erosi yang terjadi pada berbagai penggunaan lahan di DAS Pitu Riase Kabupaten Sidrap?; 2) Bagaimana laju erosi yang dapat ditoleransikan (TSL) di DAS Pitu Riase Kabupaten Sidrap?; 3) Bagaimana indeks bahaya erosi (IBE) di DAS Pitu Riase Kabupaten Sidrap?; 4) Bagaimana arahan/ rekomendasi penggunaan lahan di DAS Pitu Riase Kabupaten Sidrap? DAS Pitu Riase Kabupaten Sidrap. 3) Menganalisis Indeks Bahaya Erosi (IBE) di Sub DAS Pitu Riase Kabupaten Sidrap. 4) Menentukan arahan/ rekomendasi penggunaan lahan di Sub DAS Pitu Riase Kabupaten Sidrap.

\section{METODE PENELITIAN}

Penentuan Unit Lahan dilakukan Untuk menentukan unit lahan di lokasi penelitian digunakan peta jenis tanah, peta kemiringan lereng dan peta penggunaan lahan dengan skala yang sama kemudian di Overlay dengan menggunakan program ARC GIS 10.3 sehingga didapatkan satuan unit lahan. Di sisi lain dilakukan pengumpulan data sekunder yaitu data curah hujan bulanan selama 10 tahun terakhir (2006-2017) diperoleh dari Badan Klimatologi dan Geofisika (BMKG). Kemudain dilakukan analisi data yang meliputi :

\section{Prediksi Tingkat Erosi}

Prediksi tingkt erosi tanah dihitung dengan menggunakan persamaan Usle (Asdak, 2004) dengan rumus : 


$$
\mathrm{A}=\mathrm{R} \times \mathrm{K} \times \mathrm{LS} \times \mathrm{C} \times \mathrm{P} \quad \mathrm{RM}=2,21(\text { Rain })_{\mathrm{m}}{ }^{1,36}
$$

Keterangan:

$\mathrm{A}=$ besarnya kehilangan tanah (ton/ha/tahun)

$\mathrm{R}=$ Indeks erosivitas hujan $(\mathrm{kJ} / \mathrm{ha})$

$\mathrm{K}=$ Indeks erodibilitas tanah (ton $/ \mathrm{kJ}$ )

LS = Indeks panjang dan kemiringan lereng

$\mathrm{C}=$ Indeks penutupan tanah dan cara bercocok tanam

$\mathrm{P} \quad=$ Indeks tindakan konservasi tanah

a. Erovisitas Hujan (R)

Faktor Erosivitas Hujan di peroleh dari persamaan Leanvin (1975 dalam
Keterangan:

$\mathrm{RM}=$ Erosivitas Hujan Bulanan $(\text { Rain })_{\mathrm{m}}=\quad$ Curah hujan bulanan $(\mathrm{cm})$

b. Erodibilitas Tanah (K)

Besarnya nilai $\mathrm{K}$ ditentukan oleh tekstur, struktur, kadar bahan organik dan permeabilitas tanah. Penentuan nilai erodibilitas tanah dilakukan dengan menggunakan Tabel 1 untuk nilai K.

Hardjowigeno, 2007) sebagai berikut :

Tabel 1.Nilai K untuk beberapa jenis tanah di Indonesia (Arsyad,1979)

\begin{tabular}{llc}
\hline \hline No & \multicolumn{1}{c}{ Jenis Tanah } & Nilai K \\
\hline \hline 1 & $\begin{array}{l}\text { Latosol(Inceptisol,Oxic subgroup) } \\
\text { Darmaga,bahan induk volkanik } \\
2\end{array}$ & $\begin{array}{l}\text { Mediteran Merah Kuning (Alfisol) } \\
\text { Cicalengka, bahan induk volkanik }\end{array}$ \\
3 & $\begin{array}{l}\text { Mediteran (Alfisol) } \\
\text { Wonosari, bahan induk breksi dan batuan liat }\end{array}$ & 0,05 \\
& $\begin{array}{l}\text { Podsolik Merah Kuning (Ultisol) } \\
4\end{array}$ & 0,21 \\
& $\begin{array}{l}\text { Jonggol, bahan induk batuan liat } \\
5\end{array}$ & $\begin{array}{l}\text { Regosol, (Inceptisol) } \\
\text { Sentolo, bahan induk batuan liat }\end{array}$ \\
6 & $\begin{array}{l}\text { Grumosol (Vertisol) } \\
\text { Blitar, bahan induk serpih (shale) }\end{array}$ & 0,15 \\
7 & $\begin{array}{l}\text { Podsolik Merah Kuning Pekalongan (Udults) } \\
8\end{array}$ & 0,11 \\
\hline \hline
\end{tabular}

c. Faktor Panjang dan Kemiringan suatu tanah dapat dihitung dengan Lereng.

persamaan sebagai berikut :

Penentuan faktor lereng yaitu $\mathrm{LS}=\sqrt{\mathrm{L}}(0,0138+0,00965$ panjang lereng (L) dan kemiringan lereng $\left.\mathrm{S}+0,00138 \mathrm{~S}^{2}\right)$

(S), dihitung secara bersama-sama.

Keterangan :

$\mathrm{L}=$ Panjang lereng $\mathrm{S} \quad=\quad$ Kemiringan lereng $(\%)$ 


\section{d. Pengelolaan Lahan ( C )}

Tabel 2.Nilai Faktor Pengelolaan Berbagai jenis Tanaman (C)

\begin{tabular}{|c|c|c|}
\hline No & Macam Penggunaan Lahan (PL) & Nilai C \\
\hline 1. & Tanah terbuka, tanpa tanaman & 1,000 \\
\hline 2. & Hutan atau semak belukar & 0,001 \\
\hline 3. & Savannad dan prairie dalam kondisi baik & 0,010 \\
\hline 4. & Savannad dan prairie yang rusak untuk gembalaan & 0,100 \\
\hline 5. & Sawah & 0,010 \\
\hline 6. & Tegalan tidak dispesifikasi & 0,700 \\
\hline 7. & Ubi Kayu & 0,800 \\
\hline 8. & Jagung & 0,700 \\
\hline 9. & Kedelai & 0,399 \\
\hline 10. & Kentang & 0,400 \\
\hline 11. & Kacang Tanah & 0,200 \\
\hline 12. & Padi Gogo & 0,561 \\
\hline 13. & Tebu & 0,200 \\
\hline 14. & Pisang & 0,600 \\
\hline 15. & Akar Wangi (sereh wangi) & 0,400 \\
\hline 16. & Rumput Bede (tahun pertama) & 0,287 \\
\hline 17. & Rumput Bede (tahun kedua) & 0,002 \\
\hline 18. & Kopi dengan penutup tanah buruk & 0,200 \\
\hline 19. & Talas & 0,850 \\
\hline \multirow[t]{4}{*}{20.} & Kebun Campuran : & \\
\hline & - Kerapatan Tinggi & 0,100 \\
\hline & - Kerapatan Sedang & 0,200 \\
\hline & - Kerapatan Rendah & 0,500 \\
\hline 21. & Perladangan & 0.400 \\
\hline \multirow[t]{3}{*}{22.} & Hutan Alam: & \\
\hline & - Serasah Banyak & 0,001 \\
\hline & - Serasah Sedikit & 0,005 \\
\hline \multirow[t]{3}{*}{23.} & Hutan Produksi : & \\
\hline & -Tebang Habis & 0,500 \\
\hline & -Tebang Pilih & 0,200 \\
\hline 24. & Semak belukar, padang rumput & 0,300 \\
\hline 25. & Ubi Kayu + Kedelai & 0,181 \\
\hline 26. & Ubi Kayu + Kacang Tanah & 0,195 \\
\hline 27. & Padi-Sorghum & 0,345 \\
\hline 28. & Padi-Kedelai & 0,417 \\
\hline 29. & Kacang Tanah + Gude & 0.495 \\
\hline 30. & Kacang Tanah + Kacang Tunggak & 0,571 \\
\hline 31. & Kacang Tanah + Mulsa Jerami 4th/ha & 0,049 \\
\hline 32. & Padi + Mulsa Jerami 4th/ha & 0,096 \\
\hline 33. & Kacang Tanah + Mulsa Jagung 4th/ha & 0,128 \\
\hline 34. & Kacang Tanah + Mulsa Crotalaria 3th/ha & 0,136 \\
\hline 35. & Kacang Tanah + Mulsa Kacang Tunggak & 0,259 \\
\hline 36. & Kacang Tanah + Mulsa Jerami 2t/ha & 0,377 \\
\hline 37. & Padi + Mulsa Crotalari 3t/ha & 0,387 \\
\hline 38. & Pola Tanaman Tumpang Gilir + Mulsa Jerami & 0,079 \\
\hline 39. & Pola Tanaman Berurutan + Mulsa Sisa Tanaman & 0,357 \\
\hline 40. & Alang-alang murni subur & 0,001 \\
\hline 41. & Padang rumput (syepa) dan savanna & 0,001 \\
\hline 42 & Rumput Brachiaria & 0,002 \\
\hline
\end{tabular}

Sumber : Arsyad (2010) 

e. Upaya Pengelolaan Konservasi (P)

Nilai faktor tindakan konservasi tanah $(\mathrm{P})$ adalah nisbah antara besarnya erosi dari lahan dengan suatu tindakan konservasi tertentu terhadap besarnya erosi pada lahan tanpa tindakan konservasi dalam keadaan identik.
Termasuk dalam tindakan konservasi tanah adalah pengolahan tanah menurut kontur, guludan, dan teras. (Suripin, 2004). Nilai faktor P untuk berbagai tindakan konservasi tanah dapat di lihat pada Tabel 3.

Tabel 3.Nilai Faktor Upaya Pengelolaan Konservasi (P)

\begin{tabular}{|c|c|c|}
\hline No & Teknik Khusus Konservasi Tanah & Nilai P \\
\hline 1. & Tanpa Tindakan Pengandalian Erosi & 1,000 \\
\hline \multirow{4}{*}{2.} & Teras bangku :- konstruksi baik & 0,040 \\
\hline & - konstruksi sedang & 0,150 \\
\hline & - konstruksi kurang baik & 0,350 \\
\hline & - teras tradisional & 0,400 \\
\hline \multirow{4}{*}{3.} & Strip tanaman : & \\
\hline & - rumput Bahlia & 0,400 \\
\hline & - Clotararia & 0,640 \\
\hline & - Dengan Kontur & 0,200 \\
\hline \multirow{4}{*}{4.} & $\begin{array}{l}\text { Pengelolaan Tanah dan Penanaman menurut Gari } \\
\text { - kemiringan } 0-8 \%\end{array}$ & \\
\hline & - kemiringan $8-20 \%$ & 0,500 \\
\hline & - kemiringan $>20 \%$ & 0,750 \\
\hline & & 0,900 \\
\hline
\end{tabular}

2. Erosi yang dapat ditoleransikan

Erosi yang dapat ditoleransikan atau dikenal dengan istilah TSL dapat dihitung dengan rumus :

$$
\mathrm{TSL}=\frac{\boldsymbol{K E} \cdot \boldsymbol{F K}}{\boldsymbol{U} G \boldsymbol{T}}
$$

Keterangan :

$\mathrm{KE}=$ Kedalaman Efektif Tanah (mm)

FK = Faktor Kedalaman Sub-Ordo Tanah UGT = Umur Guna Tanah (untuk kepentingan pelestarian digunakan 400 tahun).
3. Indeks Bahaya Erosi (IBE)

$$
\begin{aligned}
& \text { Indeks Bahaya Erosi }= \\
& \frac{\text { Erosi Potensial }(\mathrm{A})}{\mathrm{T}}
\end{aligned}
$$

Keterangan:

$\mathrm{A}=$ Laju Erosi yang diperkirakan menurut USLE(ton/ha/tahun)

$\mathrm{T}=$ Erosi yang dapat ditoleransikan (ton/ha/tahun) 
Tabel 4. Kriteria Penetapan Indeks Bahaya Erosi

\begin{tabular}{lll}
\hline \hline No & \multicolumn{1}{c}{ Nilai IBE } & Kriteria IBE \\
\hline \hline 1 & $<1.0$ & Ringan \\
2 & $1.01-4.0$ & Sedang \\
3 & $4.01-10$ & Berat \\
4 & $>10.01$ & Sangat Berat \\
\hline \hline
\end{tabular}

Sumber : Hammer 1981 dalam Arsyad 2010.

4. Rekomendasi / Arahan penggunaan lahan

Arahan penggunaan lahan di Sub DAS Pitu Riase, didasarkan pada perbaikan penggunaan lahan, dengan perubahan nilai $\mathrm{C}$ dan $\mathrm{P}$ sehingga diperoleh penggunaan lahan yang tidak rusak dan berkelanjutan.

\section{HASIL DAN PEMBAHASAN}

\section{A. Unit Lahan Sub DAS Pitu Riase}

Lokasi penelitian yang dipilih adalah DAS Bila khususnya Sub DAS Pitu Riase. Luas Sub Das Pitu Riase yaitu 1694,088 Ha. Wilayah administrasi Sub DAS Pitu Riase meliputi Kelutahan Batu, Desa Lagading, Desa Botto, Desa Bola Bulu, Desa Compong, Desa Lombo, Desa Leppangeng, Desa Tanatoro, Desa Bila Riase, Desa Buntu buangin, Desa Belawae dan Desa Dengeng-Dengeng. Setelah dilakukan overlay dengan menggunakan peta jenis tanah, peta kemiringan lereng, dan peta penggunaan lahan, maka unit lahan yang terbentuk pada beberapa penutupan lahan adalah sebanyak 59 unit lahan.

\section{B. Prediksi Tingkat Erosi Metode USLE (Universal Soil Loss Equation)}

1. Faktor Erosivitas Curah Hujan (R)

Curah hujan merupakan ketinggian air hujan yang jatuh pada tempat yang datar dengan asumsi tidak menguap, tidak meresap dan tidak mengalir. Nilai erosivitas hujan stasiun Lawawoi/watan pulu Kabupaten Sidrap selama 10 tahun (2008-2017) sebesar $1.317 \mathrm{~mm}$. Nilai tersebut diperoleh berdasarkan hasil perhitungan curah hujan selama 10 tahun dengan menggunakan persamaan lenvain. Persamaan lenvain digunakan karna data yang tersedia hanya jumlah curah hujan bulanan. Hal ini berasarkan pernyataan Bols (1978), bahwa Faktor Erosivitas Hujan dapat dihitung dengan rumus lenvain bila data jumlah hujan harian maksimum rata-rata $(\text { Max.P })_{m}$ dan banyaknya hari hujan tidak tersedia.

Curah hujan di Sub DAS Pitu Riase tergolong sedang, namum tetap menyebabkan terjadinya erosi akibat rusaknya lapisan permukaan tanah karena 
pukulan air hujan. Hujan yang terjadi infiltrasi menurun. Peningkatan intensitas dengan intensitas yang cukup tinggi dan hujan akan meningkatkan aliran dalam jangka waktu yang relatif lama permukaan sehingga daya angkut partikel berpotensi menyebabkan terjadinya erosi. - partikel tanah meningkat sehingga Hal itu terjadi karena tanah akan selalu proses erosi semakin besar. Hal ini sesuai mengalami perubahan-perubahan baik pernyataan Utomo (1994), bahwa dari segi fisik, kimia maupun biologi. Intensitas hujan yang tinggi akan memiliki Perubahan dari segi fisik misalnya energi yang besar dalam menghancurkan kerusakan lapisan permukaan tanah akibat agregat tanah sehingga proses erosi pukulan air hujan yang mengakibatkan semakin besar. Adapun Letak secara hancurnya agregat tanah yang akan geografis dan sebaran luas areal stasiun menyumbat pori-pori tanah sehingga dapat dilihat pada Tabel 5.

Tabel 5. Wilayah Hujan Sub DAS Pitu Riase dan Nilai Erosivitas (R)

\begin{tabular}{llc}
\hline No. & \multicolumn{1}{c}{ Uraian } & Stasiun Lawowoi \\
\hline \hline 1 & Lokasi & $119^{0} 44^{\prime} 30,1^{\prime}$ \\
& a. Longitude & $03^{0} 54^{\prime} 19,2^{\prime}$ \\
2 & b. Latitude & $1.317,017$ \\
3 & Nilai R (mm/thn) & $1.694,088$ \\
\hline \hline
\end{tabular}

Sumber: Data Sekunder BMKG

2. Faktor Erodibilitas Tanah (K)

Faktor Erodibilitas tanah merupakan salah satu faktor yang mempengaruhi besar kecilnya erosi yang terjadi pada suatu lahan. Tanah dengan erodibilitas tinggi akan lebih mudah tererosi dibandingkan dengan tanah yang erodibilitasnya lebih rendah, dimana berikut: faktor erodibilitas (K) menunjukkan resistensi partikel tanah terhadap pengelupasan dan perpindahan partikelpartikel tanah oleh adanya energi kinetik air hujan. Adapun Jenis Tanah yang tersebar di sekitar kawasan Sub DAS Pitu Riase dapat dilihat pada Tabel 6 sebagai 
Andi Nurhawaidah : Arahan Pengelolaan Daerah Aliran Sungai berdasarkan Indeks Bahaya Erosi (IBE) Sub DAS Pitu Riase Kabupaten Sidrap

Tabel 6. Jenis Tanah berdasarkan USDA dan Nilai Erodibilitas Tanah (K) Sub DAS Pitu Riase

\begin{tabular}{clrrr}
\hline \hline No & Jenis Tanah & Nilai K & *Luas (ha) & *Luas (\%) \\
\hline \hline 1. & Dystropepts & 0,20 & 1559,884 & $92 \%$ \\
2. & Paleudults & 0,32 & 71,948 & $4 \%$ \\
3. & Tropudalfs & 0,23 & 62,255 & $4 \%$ \\
\hline TOTAL & & & $1.694,09$ & $100 \%$ \\
\hline
\end{tabular}

Sumber: Sumber: Hasil Analisa SIG, 2018

Jenis tanah yang tersebar di sekitar pendapat Utomo (1994), bahwa kepekaan Sub DAS Pitu Riase yaitu Dystropepts, suatu tanah terhadap erosi atau nilai Paleudults, dan Tropudalfs. Tanah di Sub erodibililtas suatu tanah ditentukan oleh DAS Pitu Riase didominasi tanah ketahanan tanah terhadap daya rusak dari Dystropepts sebesar 92\%, diikuti luar dan kemampuan tanah untuk Paleudults dan Tropudalfs sebesar 4\%. menyerap air (Infiltrasi).

Jenis tanah pada Sub DAS Pitu 3. Faktor Panjang dan Kemiringan Lereng Riase didominasi oleh jenis tanah (LS)

Dystropepts dengan nilai erodibilitas 0,20 sebesar 1559,884 ha. Jenis tanah Dystropepts memiliki struktur tanah granuler sedang. Tanah yang bertekstur kasar mempunyai kapasitas infiltrasi yang tinggi, sedangkan tanah yang bertekstur halus mempunyai kapasitas infiltrasi kecil sehingga dengan curah hujan yang rendah pun akan menimbulkan limpasan berikut:

permukaan. Hal ini sesuai dengan

Panjang dan kemiringan lereng (LS) merupakan ukuran kemiringan lahan relative terhadap bidang datar yang secara umum dinyatakan dalam persen. Keadaan topografi suatu lahan akan berpengaruh terhadap besar kecilnya erosi yang terjadi. Adapun keadaan topografi Sub DAS Pitu Riase dapat dilihat pada Tabel 7 sebagai

Tabel 7. Keadaan topografi Sub DAS Pitu Riase

\begin{tabular}{cccc}
\hline \hline No & Lereng $(\boldsymbol{\%})$ & Topografi & Luas $($ Ha) \\
\hline \hline 1 & $0-8$ & Datar & 352,96 \\
2 & $8,-15$ & Landai & 276,92 \\
3 & $15-25$ & Agak Curam & 790,48 \\
4 & $25-40$ & Curam & 273,73 \\
\hline \hline
\end{tabular}

Sumber: Hasil Analisa SIG, 2018. 
Topografi Sub DAS Pitu Riase sehingga pengikisan terhadap bagianmenujukkan topografi agak curam yang bagian tanah akan semakin besar. dominan dengan luas 790,48 Ha. 4. Faktor Pengelolaan Tanaman (C) Topografi yang curam menyebabkan air Faktor pengelolaan tanaman hujan yang mengenai permukaan tanah merupakan salah satu faktor yang beperan mengalir lebih cepat sehingga penting dalam menekan erosi yang terjadi. kemungkinan terjadinya pengikisan Besar kecilnya erosi berkaitan erat dengan bagian tanah akan semakin besar jenis pengelolaan lahan misalnya menyebabkan erosi yang terjadi juga penanaman beberapa jenis vegetasi yang semakin besar. Hal ini sesuai dengan kemudian akan berpengaruh terhadap pernyataan (Kartasapoetra, 1988), bahwa kondisi permukaan tanah, dimana pohon Semakin panjang lereng dan kemiringan yang tumbuh akan meminimalisir lereng maka kerusakan dan penghancuran terjadinya penghancuran agregat-agregat atau berlangsungnya erosi akan lebih tanah oleh pukulan air hujan. Pengunaan besar. Dimana semakin panjang lereng lahan di sekitar kawasan Sub DAS Pitu pada tanah akan semakin besar pula Riase dapat dilihat pada Tabel 8, sebagai kecepatan aliran air di permukaannya berikut :

Tabel 8. Pengelolaan Lahan Sub DAS Pitu Riase dan Nilai C

\begin{tabular}{clrrr}
\hline No & \multicolumn{1}{c}{ Pemanfaatan Lahan } & Nilai C & Luas (Ha) & Luas (\%) \\
\hline \hline 1 & Hutan Lahan Kering Primer & 0,001 & 277,56 & 16,4 \\
2 & Hutan Lahan Kering Sekunder & 0,005 & 1009,12 & 59,6 \\
3 & Pertanian Lahan Kering Campur & 0,421 & 405,18 & 23,9 \\
4 & Semak Belukar & 0,300 & 2,27 & 0,1 \\
\hline \hline & Jumlah & & $\mathbf{1 6 9 4 , 1 3}$ & $\mathbf{1 0 0 , 0}$ \\
\hline \hline
\end{tabular}

Sumber: Sumber: Hasil Analisa SIG, 2018

Pada Tabel 8 terlihat bahwa erosi yang terjadi pada pertanian lahan kering campur lebih besar daripada pemanfaatan lahan yang lain. Hal itu terjadi karena pada pertanian lahan kering campur tidak ada vegetasi pohon yang menutupi tanah sehingga air hujan yang jatuh langsung mengenai permukaan tanah, berbeda dengan hutan lahan kering yang memiliki banyak pohon sehingga erosi yang terjadi lebih kecil mengingat pohon memiliki tajuk yang dapat mengurangi laju air hujan yang jatuh ke permukaan tanah. Selain itu, sistem perakaran pada pohon 
juga mampu menyerap dan menampung air hujan pada pori-pori tanah yang terbentuk oleh akar. Hal ini sesuai dengan pendapat Kartasapoetra (1989) bahwa pertumbuhan yang rimbun (pohon-pohon di hutan lebat) dan rapat pada tanaman rendah dan rumput-rumputan erosi dapat lebih dihambat atau dicegah.

\section{Faktor Konservasi Tanah (P)}

Besarnyafaktor konservasi tanah menunjukkan jenis aktivitas pengolahan tanah seperti pencangkulan dan persiapan tanah lainnya. Adapun Konservasi tanah di sekitar kawasan Sub DAS Pitu Riase dapat dilihat pada Tabel 9, sebagai berikut:

Tabel 9. Penggunaan Lahan Sub DAS Pitu Riase dan Nilai P

\begin{tabular}{clrrr}
\hline No & \multicolumn{1}{c}{ Pemanfaatan Lahan } & Nilai P & \multicolumn{1}{c}{ Luas (Ha) } & \multicolumn{1}{c}{ Luas (\%) } \\
\hline 1 & Hutan Lahan Kering Primer & 1,00 & 277,56 & 16,4 \\
2 & Hutan Lahan Kering Sekunder & 1,00 & 1009,12 & 59,6 \\
3 & Pertanian Lahan Kering Campur & 0,35 & 405,18 & 23,9 \\
4 & Semak Belukar & 1,00 & 2,27 & 0,1 \\
\hline \hline & Jumlah & & $\mathbf{1 6 9 4 , 1 3}$ & $\mathbf{1 0 0 , 0}$ \\
\hline \hline
\end{tabular}

Sumber: Sumber: Hasil Analisa SIG, 2018

Nilai faktor konservasi tanah ditentukan dengan menggunakan tabel $\mathrm{P}$. Efektifitas tindakan konservasi dalam mengendalikan erosi tergantung pada panjang dan kemiringan lereng. Lahan di Sub DAS Pitu Riase dominan tanpa tindakan pengendalian erosi $(1,0)$. Hal ini dapat dilihat pada Tabel 9, hutan lahan kering primer dan sekunder tidak dilakukan tindakan konservasi. Hal ini menunjukkan bahwa Upaya penerapan teknik konservasi tanah di Sub DAS Pitu Riase belum optimal karena belum menerapkan tindakan konservasi.

\section{Erosi yang ditoleransikan - TSL (Tolerable Soil Loss)}

Setiap lahan pertanian akan mengalami erosi, namun erosi yang terjadi ada yang masih bisa ditoleransikan dan ada yang sudah tergolong erosi besar. Erosi yang masih bisa ditolerir dikenal dengan istilah TSL. Nilai TSL suatu lahan menunjukkan seberapa besar erosi yang terjadi dalam jangka waktu tertentu tidak mengurangi produktifitas lahan pertanian. Adapun Nilai TSL (Tolerable Soil Loss) ditujukan pada Tabel 10. 
Andi Nurhawaidah : Arahan Pengelolaan Daerah Aliran Sungai berdasarkan Indeks Bahaya Erosi (IBE) Sub DAS Pitu Riase Kabupaten Sidrap

Tabel 10. Nilai TSL Setiap Penutupan Lahan Sub DAS Pitu Riase

\begin{tabular}{|c|c|c|c|c|c|c|c|c|}
\hline No & Penutupan Lahan & $\mathbf{K E}$ & FK & UGT & $\begin{array}{c}\text { TSL } \\
\text { (Ton/ha/thn) }\end{array}$ & $\begin{array}{c}\text { Erosi } \\
\text { (Ton/ha/thn) }\end{array}$ & $\begin{array}{c}\text { Luas } \\
\text { (ha) }\end{array}$ & Ket. \\
\hline 1. & $\begin{array}{l}\text { Hutan Lahan Kering } \\
\text { Primer }\end{array}$ & 350 & 1,00 & 400 & 11,99 & 1,84 & 277,56 & Baik \\
\hline 2. & $\begin{array}{l}\text { Hutan Lahan Kering } \\
\text { Sekunder }\end{array}$ & 350 & 1,00 & 400 & 11,64 & 4,97 & 1009,12 & Baik \\
\hline 3. & $\begin{array}{l}\text { Pertanian Lahan } \\
\text { Kering Campur }\end{array}$ & 300 & 0,90 & 400 & 8,96 & 85,37 & 405,18 & Rusak \\
\hline 4. & Semak Belukar & 350 & 1,00 & 400 & 11,35 & 58,03 & 2,27 & Rusak \\
\hline
\end{tabular}

Sumber: Sumber: Hasil Analisa SIG, 2018

Nilai TSL hutan lahan kering sekunder dan Hutan lahan kering primer masih lebih besar dari erosi yang terjadi, artinya erosi masih bisa ditolerir sehingga lahan masih tetap produktif. Berbeda dengan nilai TSL untuk Pertanian lahan kering campur adalah sebesar 8,96 ton/ha/thn dimana erosi yang terjadi lebih besar yaitu 85,37 ton/ha/thn. Begitupun dengan semak belukar dimana nilai TSL sebesar 11,35 ton/ha/thn dan erosi yang terjadi sebesar 58,03 ton/ha/thn. Hal ini menunjukkan bahwa erosi yang terjadi sudah melebihi batas nilai erosi yang ditoleransikan sehingga dapat mengganggu produktifitas tanaman, dengan demikian maka hipotesis 2 diterima. TSL perlu diketahui agar dapat dikontrol kecepatan erosi yang terjadi tidak melebihi laju pembentukan tanah sehingga tidak menganggu keseimbangan alam mengingat tidaklah mungkin menekan laju erosi menjadi nol. Hal ini sesuai pernyataan Utomo(1994), Erosi yang diperbolehkan adalah kecepatan erosi yang masih berada dibawah laju pembentukan tanah. Terjadinya erosi pada suatu lahan tidak dapat dihentikan sehingga tidak terjadi erosi sama sekali. Pengendalian erosi dimaksudkan agar erosi yang terjadi tidak menganggu keseimbangan alam. Erosi di lahan pertanian dibatasi pada tingkat dimana erosi tidak menganggu produktivitas tanaman.

\section{Indeks BahayaErosi (IBE)}

Indeks bahaya erosi menunjukkan besarnya bahaya erosi yang terjadi pada suatu lahan. Indeks bahaya erosi dapat terbagi menjadi 4 kelas yaitu rendah, sedang, tinggi, dan sangat tinggi. Nilai IBE setiap penutupan lahan Sub DAS Pitu Riase dapat dilihat pada Tabel 11 berikut : 
Andi Nurhawaidah : Arahan Pengelolaan Daerah Aliran Sungai berdasarkan Indeks Bahaya Erosi (IBE) Sub DAS Pitu Riase Kabupaten Sidrap

Tabel 11. Nilai IBE Setiap Penutupan Lahan Sub DAS Pitu Riase

\begin{tabular}{clcccc}
\hline \hline No & \multicolumn{1}{c}{ Penutupan Lahan } & $\begin{array}{c}\text { Erosi Aktual } \\
(\mathbf{T o n} / \mathbf{h a} / \mathbf{t h n})\end{array}$ & $\begin{array}{c}\text { TSL } \\
(\text { Ton/ha/thn) }\end{array}$ & IBE & Ket. \\
\hline 1. & Hutan Lahan Kering Primer & 1,84 & 11,99 & 0,15 & Ringan \\
2. & Hutan Lahan Kering Sekunder & 4,97 & 11,73 & 0,42 & Ringan \\
3. & Pertanian Lahan Kering & 85,37 & 8,96 & 9,53 & Berat \\
4. & Campur & 58,03 & 11,35 & 5,11 & Berat \\
\hline \hline
\end{tabular}

Sumber: Sumber: Hasil Analisa SIG, 2018

Nilai Indeks bahaya erosi pada pertanian lahan kering campur dan semak belukar tergolong berat sehingga dibutuhkan tindakan konservasi. Dengan demikian hipotesis 3 diterima. Sementara nilai IBE hutan lahan kering primer dan hutan lahan kering sekunder tergolong rendah. Hal itu terjadi karena hutan memiliki banyak vegetasi/pohon yang membantu penyerapan air masuk kedalam tanah sehingga mengurangi terjadinya erosi lahan menyebabkan nilai IBE rendah. Hal ini sesuai dengan pernyataan Daud (2007) bahwa secara alami, hutan (baik hutan homogen maupun hutan heterogen) merupakan suatu bentuk tutupan lahan yang paling efektif untuk mengurangi kemungkinan terjadinya erosi. Hal ini berkaitan erat dengan kemampuan meresapkan air ke dalam tanah ditentukan sifat fisik tanah yang menyangkut kemampuannya untuk melakukan dan menyimpan air. Serasah, bahan organik tanah, sistem perakaran tumbuhan, serta fauna tanah amat berperan dalam memperbesar kapasitas imbuhan air kedalam tanah. Celah dan lubang-lubang yang disebabkan oleh akar tanaman dan aktivitas organisme tanah akan meningkatkan porositas tanah.

\section{E. Rekomendasi/ Arahan Penggunaan Lahan}

Erosi yang terjadi pada suatu lahan dipengaruhi oleh beberapa faktor. Salah satu faktor yang dapat dikendalikan adalah faktor vegetasi dan faktor pengolahan lahan. Faktor pengolahan (P)berkaitan dengan tindakan konservasi pada suatu lahan sedangkan nilai vegetasi (C)berkaitan dengan kemampuan tanaman untuk menutup tanah. Hal ini sesuai pernyataan Arsyad (2010) bahwa, salah satu factor yang mempengaruhi terjadinya erosi dan merupakan faktor yang dapat dikendalikan adalah faktor vegetasi. Vegetasi penutup tanah dapat memperlambat terjadinya proses erosi dan dapat menghambat pengangkutan partikel 
tanah. Faktor vegetasi dalam untuk terinfiltrasi ke dalam tanah rendah. mengendalikan erosi tergantung jenis Tinggi tanaman juga berperan dalam tanaman, umur, perakaran, tajuk peningkatan efektifitas tanaman penutup tanaman dan tinggi tanaman. Tanaman dalam mengurangi erosi.

yang mempunyai akar serabut lebih Erosi yang terjadi pada hutan lahan efektif dalam mengendalikan proses kering primer dan semak belukar terjadinya erosi, hal ini disebabkan mengalami penurunan setelah dilakukan karena benang-benang halus pada akar konservasi. Hal ini menunjukkan bahwa serabut mampu mengikat butir- butir tindakan konservasi yang dilakukan tanah menjadi agregat tanah yang mampu menurunkan laju erosi pada batas mantap. Fase pertumbuhan (umur) tanaman juga mempunyai pengaruh yang berbeda terhadap proses pengendalian erosi. Pada awal pertumbuhan tanaman penutupan tajuk masih relatif terbuka, sehingga menyebabkan air hujan yang jatuh langsung menuju permukaan tanah. Hal ini dapat mempercepat terjadinya yang seharusnya sehingga produksi lahan masih bisa optimal. Adapun tindakan konservasi yang dilakukan pada pertanian lahan kering campur adalah penambahan mulsa pada lahan pertanian yakni sisa-sisa tanaman atau tumbuhan dipotong-potong kemudian disebar secara merata pada lahan pertanian.

aliran permukaan karena kesempatan air

Tabel 12. Nilai Rataan Perbandingan Besarnya Erosi Aktual dan erosi setelah konservasi pada berbagai penutupan lahan di Sub DAS Pitu Riase

\begin{tabular}{cccccccr}
$\begin{array}{c}\text { Penutupan } \\
\text { Lahan }\end{array}$ & $\begin{array}{c}\text { Luas } \\
\text { Lahan }\end{array}$ & $\begin{array}{c}\text { Erosi } \\
\text { (Ton/ha/thn) }\end{array}$ & $\begin{array}{c}\text { TSL } \\
\text { (Tom/ha/thn) }\end{array}$ & $\begin{array}{c}\text { Metode } \\
\text { Konservasi }\end{array}$ & Nilai CP & $\begin{array}{c}\text { Erosi setelah } \\
\text { konservasi }\end{array}$ & IBE \\
\hline \hline Hs & 212,57 & 12,512 & 11,99 & $\begin{array}{c}\text { Hutan Alam } \\
\text { Serasah Banyak } \\
(0,001)\end{array}$ & 0,001 & 2,269 & 0,21 \\
\hline \hline Pc & 282,60 & 11,70 & 8,23 & $\begin{array}{c}\text { penambahan } \\
\text { mulsa }(0,079)\end{array}$ & 0,027 & 2,196 & 0,29 \\
\hline Pc & 122,58 & 120,03 & 9,31 & $\begin{array}{c}\text { penambahan } \\
\text { mulsa }(0,079)+ \\
\text { Teras gulud (0,01) }\end{array}$ & 0,001 & 0,644 & 0,07 \\
\hline \hline & 2,23 & 58,03 & 11,35 & $\begin{array}{c}\text { Hutan Alam } \\
\text { Serasah Banyak } \\
(0,001)\end{array}$ & 0,001 & 0,193 & 0,02 \\
\hline
\end{tabular}

Keterangan :

$\mathrm{Hp}=$ Hutan Lahan Kering Primer

$\mathrm{Pc}=$ Pertanian Lahan Kering Campur

$\mathrm{SB}=$ Semak Belukar 
Tujuan penambahan mulsa adalah untuk mengurangi erosi yang terjadi akibat pukulan air hujan secara lansung ke tanah yang menyebabkan aliran permukaan meningkat sehingga laju erosi lahan tinggi. Selain itu, mulsa organik juga mampu memperbaiki struktur tanah sehingga aerasi menjadi lebih baik dan permeabilitas tanah juga meningkat. Hal ini sesuai pernyataan Jacks at all (1955), bahwa selain dari sisa-sisa tumbuhan, bahan lain seperti plastik, batu, dan pasir dapat digunakan sebagai mulsa. Mulsa mengurangi erosi dengan cara meredam energi hujan yang jatuh sehingga tidak merusak struktur tanah, mengurangi kecepatan dan jumlah aliran permukaan sehingga mengurangi daya kuras aliran permukaan. Mulsa juga mengurangi penguapan air dari tanah, sehingga meningkatkan kandungan air tanah. Mulsa organik berasal dari sisa-sisa tumbuhan merupakan sumber energi yang akan meningkatkan kegiatan biologi tanah dan dalam proses perombakannya akan terbentuk senyawa-senyawa organik yang berperan dalam pembentukan struktur tanah yang mantap. Oleh karena itu, kemantapan struktur tanah akan meningkat, aerasi menjadi lebih baik dan permeabilitas tanah yanag tinggi terpelihara.

\section{KESIMPULAN}

\section{A. Kesimpulan}

Berdasarkan hasil analisa secara deskriptif dan uraian-uraian yang dikemukakan pada bab-bab terdahalu, maka dapat ditarik kesimpulan sebagai berikut :

1. Besarnya tingkat erosi di Sub DAS Pitu Riase Kabupaten Sidrap adalah sebesar 1,84 ton/ha/thn pada hutan lahan kering primer, 4,97 ton/ha/thn pada hutan lahan kering sekunder, 85,37 ton/ha/thn pada pertanian lahan kering campur, dan 58,03 ton/ha/thn pada semak belukar.

2. Erosi yang dapat ditoleransikan (TSL) di Sub DAS Pitu Riase Kabupaten Sidrap yaitu 11,99 ton/ha/thn pada hutan lahan kering primer, 11,64ton/ha/thn pada hutan lahan kering sekunder, 8,96 ton/ha/thn pada pertanian lahan kering campur, dan 11,35 ton/ha/thn pada semak belukar.

3. Indeks bahaya erosi (IBE) di Sub DAS Pitu Riase Kabupaten Sidrap yaitu 0,77 (rendah) pada hutan lahan kering primer, 0,09 (rendah) pada hutan lahan kering sekunder, 9,53 (berat) pada pertanian lahan kering campur, dan 5,11 (berat) pada semak belukar. 
4. Rekomendasi penggunaan lahan di Sub DAS Pitu Riase Kabupaten Sidrap yaitu penambahan mulsa dan pembuatan teras gulud pada beberapa unit lahan pada penutupan lahan pertanian lahan kering campur, sedangkan hutan alam serasah banyak untuk beberapa unit lahan pada penutupan lahan hutan sekunder dan semak belukar

\section{B. Saran}

Disarankan bagi petani yang ingin menggunakan lahan pertanian kering campur sebaiknya melakukan tindakan konservasi seperti penambahan mulsa, pembuatan teras gulud dan reboisasi agar lahan tidak rusak dan dapat dimanfaatkan lagi (sustainable agriculture) secara optimal .

\section{DAFTAR PUSTAKA}

Arsyad, S. 1989. Konservasi Tanah dan Air. IPB. Bogor

Daud, S.S. 2007. Pengaruh Jenis Penggunaan Lahan Dan Kelas Kemiringan Lereng Terhadap Bobot Isi, Porositas Total, Dan Kadar Air Tanah Pada Sub-DAS Cikapundung Hulu. Jurusan ilmu tanah. Fakultas Pertanian Universitas Padjadjaran. Jatinangor. Hlm. 11-12.

Effendi, S.R. 2000. Pengendalian Erosi Tanah Dalam Rangka Pelestarian Lingkungan Hidup. Bumi Aksara. Jakarta.

Hadi, W.U. 1989. Konservasi Tanah di Indonesia. Rajawali Pers. Jakarta.
Hardiyatmo, H.C. 2006. Penanganan Tanah Longsor dan Erosi. Gadjah Mada University Press. Yogyakarta.

Hammer, W.I. 1981. Second Soil Consevation Consultant Report. Journal of Centre For Soil Research. AGOVINS/78/006.-Tech.Note No.10. Bogor. Indonesia.

Jacks CV, WD Brind, R Smith. 1995. Mulching. Journal Of Soil Science. Tech. Comm. No. 49 of the C. A. B.

Kartasapoetra, A. G. 1989. Kerusakan Tanah Pertanian dan Usaha untuk Merehabilitasinya. Bina Aksara. Jakarta.

Kartasapoetra, A. G. 2005. Teknologi Konservasi Tanah dan Air. Rineka Cipta .Jakarta

Martopo, S.1994. Dasar-dasar Ekologi. Program Pasca Sarjana Universitas Gadjah Mada. Yogyakarta

Morgan, R. P. C. 1996. Soil Erosion and Conservation (second edition). Longman. England

Notohadiprawiro T.1988. Tanah, Tata guna Lahan dan Tata Ruang dalam Analisis Dampak Lingkungan. PPLHUGM. Yogyakarta

Sinukaban, N. 1997. Penggunaan model WEPP untuk memprediksi erosi dalam Collate Information and Analyzed Assessment Effect on Land Use on Soil Erosion. Pusat Penelitian Hutan.

Soemarwoto, O. 1985. Ekologi, Lingkungan Hidup dan Pembangunan.Penerbit Jambatan. Jakarta.

Sudaryono. 2002. Pengelolaan daerah aliran sungai (das) terpadu, Konsep pembangunan berkelanjutan. Jurnal Teknologi Lingkungan, Vol.3, No. 2, Mei 2002: 153-158

Suripin. 2004. Pelestarian Sumber Daya Tanah dan air. Penerbit Andi. Yogyakarta. 
Utomo, W. H. 1994. Erosi dan Konservasi Tanah. Penerbit IKIP. Malang.

Widiatmaka, S. H. 2007. Evaluasi kesesuaian lahan \& perencanaan tataguna lahan. Gajah mada university press. Yogyakarta
Yasir, J.R. 2015. Analisis pembayaran Jasa Lingkungan Air bersih di Hulu DAS Latuppa Kota PalopoProvinsi Sulawesi Selatan. [Tesis] Pasca sarjana Institut Pertanian Bogor. Bogor. 